\title{
Abrasion of cement-concrete and his contents investigation
}

\author{
Sergii Tolmachov ${ }^{1, *}$, Olena Belichenko ${ }^{1}$, and Dmitrii Tolmachov ${ }^{2}$ \\ ${ }^{1}$ Kharkov National Automobile und Highway University, ul. Yaroslava Mudrogo, 25, 61002 \\ Kharkov, Ukraine \\ ${ }^{2}$ LLC "Elavtopas", ul. Gvardijciv-Shy`roninciv, 33, 61170 Kharkov, Ukraine
}

\begin{abstract}
The paper presents studies of abrasion of concretes made on various rubble: granite, syenite and limestone. The purpose of the research was to assess the wear of each element of the concrete structure and its contribution to the overall wear resistance of concrete. For this purpose, experimental studies were carried out on the wearability of coarse aggregate, cured cement paste, cement-sand mortar and concrete on different aggregates. Studies of abrasion were carried out on concretes hardened in various conditions: normal, air-dry and moisture-proof moisture (under the film). The hardening conditions of the samples play a major role in the change in abrasion and can lead to an increase in abrasion by several times. It is shown that the greatest abrasion is observed in the hardened cement test, as well as in cement-sand mortar. It is established that the wearability of a coarse aggregate from dense rocks increases with an increase in the attrition path (the number of cycles of abrasion). The abrasion of the moisture-proof moisture of the lower part of the samples from the hardened cement stone, mortar or concrete may be lower than the abrasion of the upper, not protected from evaporation of moisture.
\end{abstract}

\section{State of the issue}

\subsection{Analysis of studies and publications}

Aggressive factors that influence the road cement-concrete result in its destruction [1-6]. These factors are aqueous solutions of salts, gases, heating and cooling, freezing and thawing, etc. Therefore it is important to quickly determine how external conditions affect the change, that takes place in the structure of concrete. Most of researches accept change in concrete strength as a parameter that allows for conducting such estimation.

They compare concrete strength before the beginning of effect of aggressive factors and after the fixed exposure time. However, for road concrete, strength is not always a parameter that allows for defining just how much its durability goes down. It is necessary to take into account that aggressive actions affect primarily the concrete topping that is often in a wet state, which leads to its destruction.

* Corresponding author: Tolmachov.serg@gmail.com 
The action of aggressive factors takes place jointly with the mechanical motor transport loading [7]. Under such conditions, first of all, wear-resistance decreases rather than strength. Its criterion is wearability. Combination of physicochemical and mechanical factors leads to rapid destruction of road concrete pavements [7-10].

\subsection{Relevance}

According to ideas of Prof. I.M. Grushko and other researchers, cement concrete can be viewed as a structure within another structure. Concrete structure contains cement mortar. Cement mortar structure contains hardened cement paste. Furthermore, concrete is composite material that consists of crushed stone, sand, cement and water. Wearability of each element is different, but there is very little research on this matter. For this reason, assessment of wear of each element of structure and its contribution to general wearresistance of concrete is relevant.

\section{Materials and methods of research}

In research the following typed of crushed stone were used: granite, cyenit and limestone. Fraction of crushed stone is $5-10 \mathrm{~mm}$. Crushed stone strength grade was M 1200 $(120 \mathrm{MPa})$. Fine aggregate was quartz and lime sand with fineness modulus $=2.1 \ldots 2.4$. Binding cement was of PC I 500 (CEM I 52,5) grade.

Wearability was determined on cubic samples with dimensions of $7 \times 7 \times 7 \mathrm{~cm}$. They were made of rocks as well as hardened cement paste, cement-sand mortar and concrete. Cement paste, mortars and concrete had been hardening for 28 days in different conditions. After that samples were subjected to abrasion on laboratory abrasion table (LKI-3) in accordance with standard DSTU B.2.7-212 (fig. 1, 2).

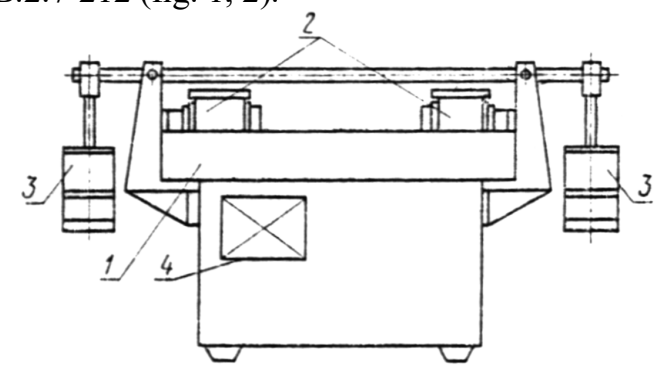

Fig. 1. Diagrammatical representation of the abrasion disk of LKI-3 type: 1 - abrasion disk; 2 - the tested samples; 3 - loading device; 4 - number of turns of disk counter

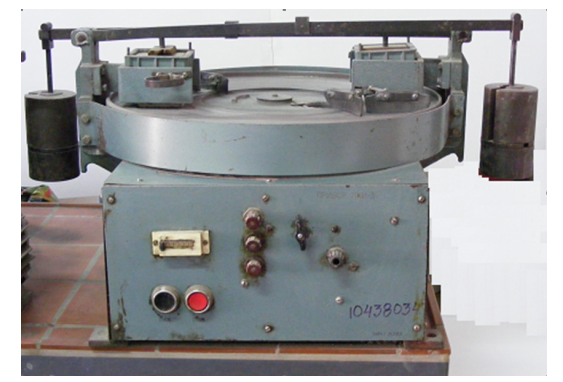

Fig. 2. The exterior of abrasion disk of LKI-3 type

According to the requirements of DSTU B.2.7-212, cubic samples were placed in two metal holders secured above the surface of the disk, so that their lower edge was on the surface of 
the disk. Vertical loading of $300 \pm 5 \mathrm{~N}$, which corresponds to a pressure of $60 \pm 1 \mathrm{kPa}$, was applied to each sample. $20 \mathrm{~g}$ of the special sand were evenly poured on the surface of the disk made from cast-iron. During tests of the water-saturated (moist) samples sand was moisturized by $15 \mathrm{~cm}^{3}$ of water. After that, the device was switched on. After 28 turns of disk, which corresponds to $30 \mathrm{~m}$ of the abrasion track, the device was switched off. Then sand and pieces of the destroyed samples were removed from the surface of disk. A new portion of sand was poured and device was switched on once again. This operation was repeated 5 times, which corresponded to 1 cycle or $150 \mathrm{~m}$ of the abrasion track.

After that samples were taken out from a holder, turned $90^{\circ}$ around vertical axis and then cycle was restarted. According to the DSTU B.2.7-212, a sample must pass 4 cycles of tests. In our research, 4 and 6 cycles of tests were conducted. According to DSTU B.2.7212 , a test must be applied only to the bottom part of sample. But in our research we tested bottom and top sides of samples.

Samples were weighed before the beginning of tests and after every cycle. Also the height of sample was measured before the beginning of tests and after every cycle.

Abrasion was determined by an Eq. (1):

$$
G=\frac{m_{1}-m_{2}}{S},
$$

where: $m_{1}$ is the mass of sample before the beginning of tests, $\mathrm{g} ; m_{2}$ is the mass of sample after the cycles of tests, g; $S$ - an area of the side of sample, that is subjected to abrasion, $\mathrm{cm}^{2}$.

During testing abrasion was applied not only to bottom but also to top side of mortar and concrete. This is due to the fact that in case of violation of conditions of hardening and absence of curing of hardening mortar or concrete, the surface of sample becomes too flimsy due to the increase of porosity in the top part of the sample. Wearability must increase in this case.

\section{Experimental research}

The results of tests of wearability of coarse aggregate, hardened cement paste, cement-sand mortar and concrete are shown in Table 1.

It is evident that magmatic rock aggregates, for example, granite or syenite, wear off slowly. The maximal value of wearability of granite does not exceed 0.028 , and syenite $0.036 \mathrm{~g} / \mathrm{cm}^{2}$ after 4 test cycles and 0.036 and $0.053 \mathrm{~g} / \mathrm{cm}^{2}$ after 6 test cycles. A metamorphosed rock, such as a marble limestone, is worn down by $1.5 \ldots 2.2$ times more than magmatic rocks. It is possible to see a conformity: with the increase in a number of test cycles wearability of all rocks increases approximately by the same value. This shows high homogeneity of textures of these rocks, their high density and low porosity.

In comparison with wearability of concrete, it is possible to see that the wear of the samples made from these rocks is insignificant. Therefore, wearability of the crushed stone made from these rocks is $9 \ldots 19 \%$ comparing to the general wearability of concrete, at the wear of its friable top part. As compared with wearability of bottom side of concrete, wearability of rocks is even less and makes $4 \ldots 8 \%$ (Table. 1). Then wearability of hardened cement paste was studied.

Will abrasion investigation of hardening cement paste. Cement paste samples were hardening in a laboratory at the temperature of air $22 \ldots 25{ }^{\circ} \mathrm{C}$ and relative humidity $50 \ldots 60 \%$. No special actions on hardening cement curing were conducted. A top side of a sample was open and moisture evaporated through it. The bottom side of a sample was protected from evaporation of moisture by polyethylene. 
Investigations of the effect of various additives on the strength of concrete were carried out on equally mobile concrete mix in the Table 1 . Studies have shown that when the mineral additive is added into the concrete, strength increases, but for compressive strength and flexural strength this increase is different. The compressive strength of concrete with a mineral additive increases by only $3 . . .6 \%$ at different times of hardening. At the same time, the flexural strength of concrete with a mineral additive increases by 18,10 and $8 \%$ on 3,7 and 28 days, respectively.

Table 1. Wearability of elements of concrete structure

\begin{tabular}{|l|c|c|c|}
\hline \multirow{2}{*}{ Tape of material } & \multirow{2}{*}{$\begin{array}{c}\text { Wearability, } \\
\text { face }\end{array}$} & \multicolumn{2}{|c|}{ Wearability, $G, \mathrm{~g} / \mathrm{cm}^{2}$ before wear } \\
cycles
\end{tabular}

A distinction is obvious between wearability of the exposed top side of the sample from hardened paste and its protected top side (table. 1). After 4 cycles of tests wearability of top side was 5.6 times more. This confirms that top layer of a sample of hardened paste, from which moisture has evaporated, becomes friable and wears down easily.

After 6 cycles of wear, the difference in wearability of top and bottom sides decreased to 4.1 times. It was also found that while wearability of bottom side of sample continues to increase with increasing of number of cycles, wearability of top side decreased considerably after 4 cycles. This shows that there is a limit of thickness of a layer of heavy wear and it is possible to determine its value.

Table 2. Wearability of hardened cement paste

\begin{tabular}{|c|c|c|c|c|c|c|c|}
\hline Bottom side & \multicolumn{7}{|c|}{ cycles } \\
\hline & 0 & 1 & 2 & 3 & 4 & 5 & 6 \\
\hline Sample height, $h, \mathrm{~mm}$ & 70.1 & 69.8 & 69.6 & 69.4 & 69.2 & 69.1 & 69.0 \\
\hline Wearability, $G, \mathrm{~g} / \mathrm{cm}^{2}$ & 0 & 0.065 & 0.107 & 0.145 & 0.180 & 0.223 & 0.264 \\
\hline Top side & \multicolumn{7}{|c|}{ cycles } \\
\hline & 0 & 1 & 2 & 3 & 4 & 5 & 6 \\
\hline Sample height, $h, \mathrm{~mm}$ & 70.0 & 69.0 & 68.4 & 68.0 & 67.6 & 67.3 & 67.1 \\
\hline Wearability, $G, \mathrm{~g} / \mathrm{cm}^{2}$ & 0 & 0.587 & 0.765 & 0.886 & 1.00 & 1.04 & 1.08 \\
\hline
\end{tabular}

As can be seen from the Table. 2, the bottom side of a sample is worn down evenly, which is confirmed by data of change of wearability and height of sample. The depth of the layer of wear of bottom side of a sample does not exceed $0.9 \mathrm{~mm}$. Top layer of the sample became quit friable and is subjected to rapid wear, which is confirmed by results of the research. Experimentally determined thickness of friable zone of cement stone at 4 cycles of wear was $2.4 \mathrm{~mm}$ from the surface of sample (table 2). At the further increase of amount 
of test cycles from 4 to 6 , the wear of top side increases insignificantly, both in value and depth, reaching $2.9 \mathrm{~mm}$.

It may be noted that wearability of cement stone in relation to general wearability of concrete is quite big. For example, when comparing wearability of protected sides, wearability of concrete stands at $0.292 \mathrm{~g} / \mathrm{cm}^{2}$, and wearability of hardened cement paste reaches $0.18 \mathrm{~g} / \mathrm{cm}^{2}$, which makes $62 \%$ of general wear concrete.

When comparing wearability of unprotected sides of samples of concrete and hardened cement paste, wearability of cement sample is 3.4 times more than wear of concrete sample. This proves that even under normal conditions of hardening wearability of concrete heavily depends on wearability of hardened cement paste. Violation of the conditions of normal hardening leads to the situation when wearability of concrete primarily depends on extent of wearability of hardened cement paste.

Research has shown that wearability of protected bottom side of samples of cement mortars of different composition is significantly less than that of unprotected top side (table 1). There is the same conformity as for estimations of wearability of hardened cement paste.

Obviously, with decreasing of content of cement in the composition of mortar wearability increases for both top and bottom sides. In the mortars of compositions $\mathrm{C}: \mathrm{P}=1: 1 \ldots 1: 3$, containing $900 \ldots 450 \mathrm{~kg}$ of cement per $1 \mathrm{~m}^{3}$, wearability of bottom sides differs insignificantly $\left(0.176 \ldots 0.205 \mathrm{~g} / \mathrm{cm}^{2}\right)$. When switching to mortars of compositions $\mathrm{C}: \mathrm{P}=1: 4$ with cement consumption $350 \ldots 400 \mathrm{~kg} / \mathrm{m}^{3}$, wearability of bottom side of the sample increases significantly, 1.85 times as compared to other compositions. This can be explained by decreasing of density of solution due to the increase of porosity, and open porosity in the first place. There is even bigger difference in wearability for top sides of the samples.

Table 3. Water absorption of mortars

\begin{tabular}{|l|c|c|c|c|}
\hline Proofness of sides of & \multicolumn{4}{|c|}{ Water absorption mortar, $W, \%$, by $24 \mathrm{~h}$} \\
\cline { 2 - 5 } samples during hardening & $\mathrm{C}: \mathrm{S}=1: 1$ & $\mathrm{C}: \mathrm{S}=1: 2$ & $\mathrm{C}: \mathrm{S}=1: 3$ & $\mathrm{C}: \mathrm{S}=1: 4$ \\
\hline Both sides are protected & 3.8 & 5.1 & 6.2 & 8.5 \\
\hline Top side is open & 5.9 & 7.7 & 9.3 & 12.8 \\
\hline
\end{tabular}

In our research applied the standard method of determination of water absorption of simples was applied, in accordance with DSTU B.2.7-170:2008. According to this method, in order to determine water absorption, samples were dried to constant mass at the temperature of $105 \pm 10 \mathrm{C}^{\circ}$. Then they were cooled at the temperature of $18 \pm 2 \mathrm{C}^{\circ}$ and submerged in water at the same temperature. Samples were periodically taken out from water and weighed. According to the last weighing, in 24 hours after water-logging of samples, water absorption of mortar (concrete) on mass was determined. We used an Eq. (2):

$$
W=\frac{m_{2}-m_{1}}{m_{1}} \cdot 100 \%,
$$

where $m_{1}$ is the mass of the sample dried to constant mass; $m_{2}$ is mass of sample that had been in water for 24 hours.

Research of water absorption of mortars of different composition showed that while going from mortars of $\mathrm{C}: \mathrm{S}=1: 3$ to mortars of $\mathrm{C}: \mathrm{S}=1: 4$ there is a sharp increase in this index (Table. 3). In the case when both sides of samples of mortars of composition of $\mathrm{C}: \mathrm{S}=1: 4$ are protected from water evaporation during period of hardening, water absorption increases by $2.3 \%$ or on $37 \%$. Approximately the same increase of water absorption takes place in going from mortars of composition of $\mathrm{C}: \mathrm{S}=1: 1$ to $\mathrm{C}: \mathrm{S}=1: 3$ (increase cement content from 900 to $450 \mathrm{~kg} / \mathrm{m}^{3}$ ). A similar increase of water absorption 
takes place for mortars where bottom side wasn't protected from evaporation of moisture during period of hardening.

It can be noted that for the samples of mortars where the top side was open water absorption is 1.5 time more than for samples where both sides were protected from evaporation of moisture in the period of hardening. It confirms that the increase of wearability of mortars is proportional to the increase of open porosity of mortars. The method of water absorption allows for accurate enough estimation of a number of open pores mainly (first of all, capillar). Therefore the index of water absorption depends on a number of open pores. With the increase of an amount of evaporated moisture, the volume of open pores increases steadily. Accordingly, water absorption of samples must increase. In parallel, due to the increase of porosity, especially of the top layer of a sample, wearability will increase. Results of our research which are presented in a Table 4, confirm this.

Table 4. Wearability of cement mortars of composition of C:S $=1: 3$

\begin{tabular}{|l|c|c|c|c|c|}
\hline \multirow{2}{*}{$\begin{array}{c}\text { Conditions of } \\
\text { manufacturing }\end{array}$} & \multirow{2}{*}{$\begin{array}{c}\text { Average } \\
\text { density }\end{array}$} & \multicolumn{2}{|c|}{ Water absorption } & \multicolumn{2}{|c|}{ Wearability } \\
\cline { 3 - 6 } & & $15 \mathrm{~min}$ & $24 \mathrm{~h}$ & wearing depth & $\mathrm{G}, \mathrm{g} / \mathrm{cm}^{2}$ \\
\hline Vibroflotation & $2200 \mathrm{~kg} / \mathrm{m}^{3}$ & $6.6 \%$ & $8.0 \%$ & $2.4 \mathrm{~mm}$ & 0.523 \\
\hline Pressing with $20 \mathrm{MPa}$ & $2020 \mathrm{~kg} / \mathrm{m}^{3}$ & $4.9 \%$ & $5.8 \%$ & $2.7 \mathrm{~mm}$ & 0.538 \\
\hline Pressing with $90 \mathrm{MPa}$ & $2280 \mathrm{~kg} / \mathrm{m}^{3}$ & $3.5 \%$ & $3.9 \%$ & $1.9 \mathrm{~mm}$ & 0.418 \\
\hline
\end{tabular}

Cement mortars of composition of $\mathrm{C}: \mathrm{S}=1: 3$ were compacted at different pressure and the indexes of water absorption and readability were estimated. For this purpose vibration was applied, normal pressing at pressure $20 \mathrm{MPa}$ and hyper pressing at pressure $90 \mathrm{MPa}$. In the first 15 minutes, there is a dampness penetration of the largest open pores and capillaries. The biggest macroporosity occurs in samples that were compacted by vibration $-6.6 \%$. The least macroporosity occurs in samples that were compacted at high external pressure $-3.5 \%$ (so-called hyper pressing). Accordingly, the least wearability, both in the depth of the layer of wear $(h=1.9 \mathrm{~mm})$ and in general size $\left(G=0.418 \mathrm{~g} / \mathrm{cm}^{2}\right)$ was discovered in the hyper pressed samples. The density of these samples is higher than that of samples compacted in another ways.

The results of experiments showed that there is correlation between wearability of mortars and number of open pores in them, first of all in top side of the sample. Assuming that density of mortars with decrease in the number of binder in their composition goes down, in this case conditions for the increase of an amount of open pores are automatically created. Most of open pores are in the top part of a sample, from the surface of which moisture evaporates. Then friable top layer of a mortar wears down easier and quicker. Taking into account that most of open pores are in mortar phase, wearability of concretes with the cement consumption of more than $350 \ldots 400 \mathrm{~kg} / \mathrm{m}^{3}$ will depend on wearability of cement mortar.

The estimation of wearability of concrete was conducted on the samples of composition that is most often used for manufacturing (cement consumption is $350.400 \mathrm{~kg} / \mathrm{m}^{3}$ ). The data show (Table. 1) that wearability of such concrete is comparable to wearability of mortars with cement consumption of $400 \ldots .500 \mathrm{~kg} / \mathrm{m}^{3}$. This is true for top and bottom sides of samples and proves the assumption form above. It may also be noted that wearability of top side of concrete sample is 2.2...2.4 times higher, than that of bottom side, which correlates with similar data for a cement stone and mortars.

Taking into account that the conditions of hardening strongly affects wearability of concretes, research was conducted on wearability of samples made from concretes that were hardened in different humidity conditions (Table. 5). 
Table 5. Wearability of concretes that were hardening in various conditions

\begin{tabular}{|c|c|c|c|}
\hline \multirow{2}{*}{$\begin{array}{l}\text { Conditions } \\
\text { of concrete } \\
\text { hardening }\end{array}$} & \multirow{2}{*}{$\begin{array}{l}\text { Side under } \\
\text { wear }\end{array}$} & \multicolumn{2}{|c|}{ Wearability, $G, \mathrm{~g} / \mathrm{cm}^{2}$} \\
\hline & & $\begin{array}{l}\text { C- } 350 \mathrm{C}-1250 \mathrm{~S}-750 \mathrm{~kg} / \mathrm{m}^{3} \\
\text { (Granite crushed stone, } \\
\text { quartz sand) }\end{array}$ & $\begin{array}{l}\mathrm{C}-350 \mathrm{C}-1250 \mathrm{~S}-750 \mathrm{~kg} / \mathrm{m}^{3} \\
\text { (Limestone crushed stone and } \\
\text { sand) }\end{array}$ \\
\hline \multirow{2}{*}{ Normal } & top & 0.496 & 1.682 \\
\hline & bottom & 0.271 & 0.968 \\
\hline \multirow[t]{2}{*}{ Air-dry } & top & 0.601 & 2.025 \\
\hline & bottom & 0.365 & 1.368 \\
\hline \multirow{2}{*}{$\begin{array}{l}\text { Under the } \\
\text { tape }\end{array}$} & top & 0.368 & 1.092 \\
\hline & bottom & 0.243 & 0.912 \\
\hline
\end{tabular}

The results of experiments show the following: when hardening of samples in air-dry terms (the temperature of $25 \ldots 30 \mathrm{C}^{\circ}$ and relative humidity of $40 \ldots 50 \%$ ) wearability of top side of the samples of concretes increases by $21 \ldots 63 \%$ comparing to the wearability of samples, that were hardening in normal conditions (the temperature of $18 \ldots 22{ }^{\circ} \mathrm{C}$, and relative humidity of $95 \ldots 100 \%$ ) and were covered by polyethylene tape. This applies to the samples made on granite crushed stone and quartz sand. For the samples made on a limestone crushed stone and sand, this difference is $21 \ldots 85 \%$.

The conditions of hardening change the wearability of bottom side of samples of concrete too. The difference in wearability of samples that were hardening in air-dry conditions is $35 \%$ compared to samples that were hardening in normal conditions and $50 \%$ compared to the samples that were hardening under tape. For samples on limestone aggregates, the difference in wearability of bottom side is $41 \%$ and $50 \%$ respectively.

Analysis of data of Tables 1-5 shows that there is a critical cement consumption in the composition of concrete, and it equals $350 \ldots 450 \mathrm{~kg} / \mathrm{m}^{3}$. With reducing of expense of cement below the level of $350 \mathrm{~kg} / \mathrm{m}^{3}$ or increasing it for more than $450 \mathrm{~kg} / \mathrm{m}^{3}$ wearability increases sharply, which results in reduction of life of concrete.

With the increase in cement consumption in concretes from 250 to $450 \mathrm{~kg} / \mathrm{m}^{3}$ wearability of samples also changes. For example, for samples that were hardening in laboratory conditions, wearability of bottom side with the increase of consumption cement within the specific limits goes down from 0.332 to $0.221 \mathrm{~g} / \mathrm{cm}^{2}$, and for the top side, vice versa increases from 0.425 to $1.521 \mathrm{~g} / \mathrm{cm}^{2}$. These data are consistent with results of the above-mentioned research (Table. 1).

\section{Conclusion}

1. It was extablished that wearability of coarse aggregate from dense rocks increases with the increase of path of abrasion (number of cycles of wear) by the same value. This value is very small in comparison with the general wearability of concrete.

2. It is shown that the conditions of hardening of samples play a key role in the change of wearability and can lead to increasing of in the height of wearability by $5 \ldots 6$ times.

3. It has been proven that wearability of the protected from evaporation of moisture bottom parts of the samples, made of hardened cement stone, mortar or concrete, can be up to 6 times lower than wearability of top side, which was not protected.

4. The greatest wearability was detected for hardening cement paste, and also cementsand mortar, especially in case when hardening took place in air-dry terms.

5. Wearability of cement mortars and concretes depends on their content of binder and increases when cement consumption is less than $350 \mathrm{~kg} / \mathrm{m}^{3}$ or more than $450 \mathrm{~kg} / \mathrm{m}^{3}$. 


\section{References}

1. Luiz Fernandez, Malhotra V. Mohan, Cement, Concrete and Aggregates, 2, 87-100 (1990)

2. M. Moukwa, Cement and Concrete Research, 3, 439-446, (1990)

3. A.N. Plugin, I.G. Prokopova, S. Wild, A.A. Plugin, Goteborg: Inform Trycket AB, 4 (4iv075), (1997)

4. S.N. Tolmachev, Scientific Herald of DonGGAA, 2004-1(43), 2, 133-137 (2004)

5. I. Stark, B. Whitch, The durability of concrete (Kiev: Oranta, 2004)

6. Gheorghe Tudorie, Alexendru Pasnicu, Rev.transp.: Auto, drumuri, navig, 3-4, 65-69 (1991)

7. S.V. Shestoperov The durability of concrete and reinforced concrete constructions (Moscow: Stroyizdat, 1966)

8. E. Koskinen, Tienpaaallysteiden ongelmat. “Tie ja liikenne”, 3 (51), 116 (1981)

9. S.N. Tolmachev, I.G. Kondratyeva, A.N. Chugueenko, Scientific Bulletin of Construction, 43, 300-304 (2007)

10. S.N. Tolmachev, R.A. Grinchenko, L.D. Marakina, Scientific Bulletin of Construction, 39, 198-204 (2006) 